\title{
Adsorptive Behavior of Arsenic(III) Ions from Aqueous Solution onto Forestry and Agricultural Waste Biochar Pyrolyzed at $400^{\circ} \mathrm{C}$
}

\section{S.K. Gunatilake}

Department of Natural Resources, Faculty of Applied Sciences, Sabaragamuwa University of Sri Lanka, P.O.Box 02, Belihuloya. 70140, Sri Lanka.sksg@sab.ac.lk

\begin{abstract}
Sorption capacity of two different biochar (saw dust and rice straw) was evaluated in the recovery of arsenic from aqueous solutions. Biochar from rice straw and saw dust were obtained from pyrolysis of biomass at $400^{\circ} \mathrm{C}$. The optimum sorption conditions were studied for different concentrated monometallic system. Sorption studies were performed at different $\mathrm{pH}$, contracting time and different initial metal ion concentration in the batch mode. The optimum $\mathrm{pH}$ was 3 for recovery of $\mathrm{As}$ (III) and kinetic studies yielded an optimum equilibrium time of 50-60 minutes with an adsorbent dose of $1 \mathrm{~g} / \mathrm{L}$ and initial concentration $\sim 20 \mathrm{mg} / \mathrm{L}$ for As(III) ions. As(III) ions in aqueous solution were transported to biochar surface through adsorption and intra-particle diffusion process. Experimental data for As(III) ions was fitted a Langmuir model with $\mathrm{R}^{2}$ value for $\mathrm{As}(\mathrm{III}) \quad 0.969,0.879$ for saw dust and rice straw respectively. The Freundlich constant, $\mathrm{K}_{\mathrm{F}}$ values for removal of As(III) ions by saw dust and rice straw were $0.9127,0.8951$ respectively. The $1 / \mathrm{n}$ value for arsenic ions obtained from saw dust and rice straw were $0.209,028$ and indicate the normal sorption of As(III). The values indicated the affinity of the sorbent towards the uptake of As(III) ions were favorable and rice straw and saw dust biomass can be used to remove Arsenic(III) ions from aqueous phase.
\end{abstract}

Keywords: biochar, adsorption capacity, heavy metals, Arsenic(III)

\section{Introduction}

Recent years, biosorption methods were extensively used for removal of heavy metals from aqueous phase since such methods have been proven to be an efficient technique for the sequestration of pollutants in wastewater . Such methods are usually low cost as the absorption materials are mostly by-product of agricultural and other industrial wastes. Most of the studies related with biosorption were aiming towards the optimizing different physicochemical parameters to obtain the highest removal efficiency while 
the others were concerned the biosorption mechanism. From among these low cost biosorption materials, application of biochar is becoming extremely popular due to their high sorption capacity and availability of materials in almost unlimited amounts . Biochar, that pyrolyzed from biomass under no or very low oxygen condition are mostly stable and having a superior ability to retain heavy metals. Therefore such materials are beneficial in decreasing the bioavailability of pollutants and mitigate their ecological toxicities . Biochars made from agricultural wastes, including fruit peels, pine needles , grass, hardwood, crop straw and woodchip have been widely investigated for removing toxic heavy metals from aqueous solution replacing costly chemisorption methods.

From among different biochars obtained from agricultural byproducts, sawdust and rice straw are used extensively for heavy metals sequestration studied. Sawdust in their raw or burned form were shown excellent adsorptive behavior for heavy metals such as $\mathrm{Cu}, \mathrm{Pb}, \mathrm{Cd}$ and $\mathrm{Ni}$ from aqueous solution . Waste rice straw was also used as a biosorbent to remove heavy metals such as $\mathrm{Cu}(\mathrm{II}), \mathrm{Zn}(\mathrm{II}), \mathrm{Cd}(\mathrm{II})$ etc. from contaminated water and have shown excellent adsorptive behaviors .

Inorganic arsenic that exist in different oxidation states are highly toxic when present in water. The most important inorganic species are arsenite $\left(\mathrm{AsO}_{3}{ }^{3-}\right)$ and arsenate $\left(\mathrm{AsO}_{3}{ }^{-}\right)$, referred to as arsenic (III) and arsenic (V). The pentavalent arsenic is most stable in oxygen-rich aerobic aqueous environments while trivalent arsenite is predominate in moderately reducing anaerobic environments such as in deep groundwater. As(III) is more toxic and more mobile than $\mathrm{As}(\mathrm{V})$. Arsenic compounds are widely used as pharmaceuticals, agrochemical, and wood preservation. It is also apply in light emitting diodes (LED), glass making and semiconductor industries and wastewater of such industries may contain high content of As . The World Health Organization (WHO) guideline of $10 \mathrm{ppb}(0.01 \mathrm{mg} / \mathrm{L})$ has been adopted as the drinking water standard for As. Arsenic is a well known carcinogen but also attack other organs in the human body .

Since As species is highly toxic when present in water bodies, more attention were given to remove such contaminants using commonly available materials such as biochars from agro and other industrial wastes. This study was aimed to investigate the efficiency of different bio-residues to remove arsenic (III) from contaminated water. Biochar that produced from sawdust and rice straw were used as the adsorptive material in this study. Pyrolyzing temperature was selected as $400^{\circ} \mathrm{C}$ since it considered as an optimal condition that producing biochar for effective sorbent . 


\section{Materials and Methods}

The biochars used in this work were obtained from rice straw (Oryza sativa L.) and from saw dust (Artocarpus heterophyllus). Rice straw was collected from the field and then chopped into small pieces $(<2 \mathrm{~mm})$. Saw dust was collected from wood mills. All materials were then dried in air for 48 hours. The pyrolysis was performed in a small stainless steel pyrolyser vessel (1200 $\mathrm{cm}^{3}$ ) with a screw tight lid that fixed with $2 \mathrm{~mm}$ diameter steel tube. Pyrolyser was filled with material and flushed with nitrogen gas prior to plug the lid. The pyrolyser was kept inside a pre-heated $\left(100 \pm 5{ }^{\circ} \mathrm{C}\right)$ muffle furnace (Thermolyne- type 6000). Pyrolysis temperature was raised to $400{ }^{\circ} \mathrm{C}$ at a rate of approximately $20{ }^{\circ} \mathrm{C} \mathrm{min}^{-1}$ and held constant for four hours. After heating for 4 hour at $400 \pm 5{ }^{\circ} \mathrm{C}$, the pyrolyser was quickly taken out from the muffle furnace and was rapidly quenched in a distilled water bath at room temperature.

Pyrolyzed materials were then washed thoroughly with deionized water in order to remove any remaining dirt. Dried material were then grounded and mechanically sieved to a particle size of $<0.125 \mathrm{~mm}$ that were used for the adsorption experiments. Adsorption experiments were carried out by using batch technique to obtain equilibrium data that were performed at different $\mathrm{pH}$, contacting time and initial concentrations to obtain equilibrium isotherms for known concentrations of As(III) solutions. A stock solution of $1000 \mathrm{mg} / \mathrm{L} \mathrm{As}(\mathrm{III})$ were prepared using $\mathrm{As}\left(\mathrm{NO}_{3}\right)_{3}$ and diluted to various initial experimental concentrations. The experimental procedure was done as follows: $0.1 \mathrm{~g}$ of the powdered samples was shaken with $100 \mathrm{ml}$ of a metal ion solution whose concentration was $5 \mathrm{mg} / \mathrm{L}$. All adsorption experiments were performed at room temperature $\left(27 \pm 1.0^{\circ} \mathrm{C}\right)$ and $0.1 \mathrm{~g}$ of biochar were added to 250-ml Stoppard flasks containing $100 \mathrm{ml} \mathrm{As(III)} \mathrm{solutions} \mathrm{and} \mathrm{agitated}$ at $600 \mathrm{rpm}$. All batch isotherm tests were replicated three times and all the observations were recorded in triplicate and average values are reported. The solutions were then filtered using $0.45 \mu \mathrm{m}$ nylon fiber membrane filters and the total As(III) concentration in solution was determined by hydride generator atomic absorption spectrophotometer.

To observe the effect of $\mathrm{pH}$ for the adsorption, the solution $\mathrm{pH}$ were change from 3.0 to 9.0 using either $0.1 \mathrm{M} \mathrm{NaOH}$ or $0.1 \mathrm{M} \mathrm{HCl}$. Initial concentrations of solution were set from $5 \mathrm{mg} / \mathrm{L}$ to $30 \mathrm{mg} / \mathrm{L}$ in order to evaluate the effect of initial concentration for the adsorption on to biochar.

Large-scale adsorption processes for water treatment demand inexpensive, nontoxic, available adsorbents of known kinetic parameters and sorption characteristics. Therefore the knowledge of optimal conditions would be enabling a better process design and modeling. Thus absorption experiment variables were set as a function of initial $\mathrm{pH}$ of the solution, contact time 
and initial metal concentrations in order to obtain the optimum adsorption conditions. After selecting the optimum conditions, the amount of As(III) removed or adsorbed and the removal percentages (\%) of As(III) were calculated using mass balance equations;

$q=\frac{\left(\mathrm{C}_{0}-\mathrm{C}_{f}\right) V}{m} q=\frac{\left(\mathrm{C}_{0}-\mathrm{C}_{f}\right) V}{m}$

Removal Percentage $(\%)=\frac{\left(\mathrm{C}_{i}-\mathrm{C}_{f}\right) \cdot 100}{\mathrm{C}_{i}}$ Removal Percentage $(\%)=\frac{\left(\mathrm{C}_{i}-\mathrm{C}_{f}\right) \cdot 100}{\mathrm{C}_{i}}$

where the $\mathrm{q}$ is the amount $\mathrm{mg} / \mathrm{g}$ of $\mathrm{As}(\mathrm{III})$ adsorbed, $\mathrm{C}_{0}$ and $\mathrm{C}_{\mathrm{f}}$ are the initial and final concentrations of $\mathrm{As}(\mathrm{III})(\mathrm{mg} / \mathrm{L}), \mathrm{V}$ is the volume of solution and $\mathrm{m}$ is the weight of the biochar used for the experiment.

\section{Results and Discussion}

\section{Influence of contacting time to As(III) ions}

It was observed that adsorption capacity about $6.8 \mathrm{mg} / \mathrm{g}$ of As(III) ion from saw dust biochar was attained in first 35 minutes and concentration became almost constant after 40 minutes (Figure 1). Adsorption of arsenic onto rice straw biochar was optimum around 50 minutes duration and adsorption capacity was $5.7 \mathrm{mg} / \mathrm{g}$.

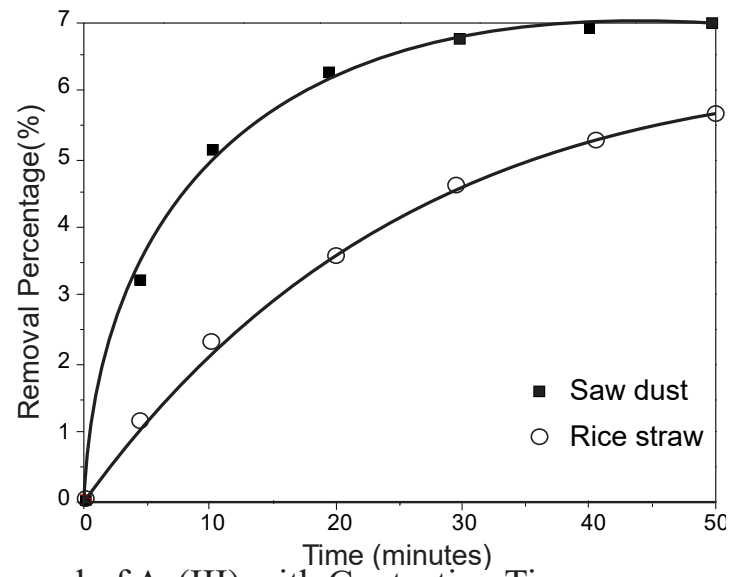

Figure 01: Removal of As(III) with Contacting Time

The fast initial uptake was observed for As(III) ions onto saw dust biochar surface due to more functional groups in the biomass. More time was consumed on diffusion of metal ions to binding sites which remains in rice straw biochar. It was concluded that 50 minutes was sufficient for sorption to attain equilibrium. 


\section{Effect of pH on As(III) adsorption}

The $\mathrm{pH}$ of a solution consider as an important parameter in the adsorption of As (III) ions onto various adsorbents. The effect of $\mathrm{pH}$ on the adsorption of As(III) ions onto biochars were investigated at initial $\mathrm{pH}$ ranging from 3.0 to 9.0. The results revealed that As(III) adsorption by biochars were highly $\mathrm{pH}$-dependent. The amount of As(III) adsorption on to rice straw biochar was increased with decreased in $\mathrm{pH}$ values. The effect of $\mathrm{pH}$ values on As(III) adsorption was more evident when rice straw biochar was used as adsorbent compared to that of sawdust (Figure 2). For instance, As(III) removal percentage (\%) for rice straw biochar was 53 at the $\mathrm{pH}$ of 3 and decreased to 17 at the $\mathrm{pH}$ of 7 when initial concentration was $10.55 \mathrm{ppb}$, whereas for sawdust the values were 35 at the $\mathrm{pH}$ of 2.5 and increased upto 59.9 at the $\mathrm{pH}$ of 7.

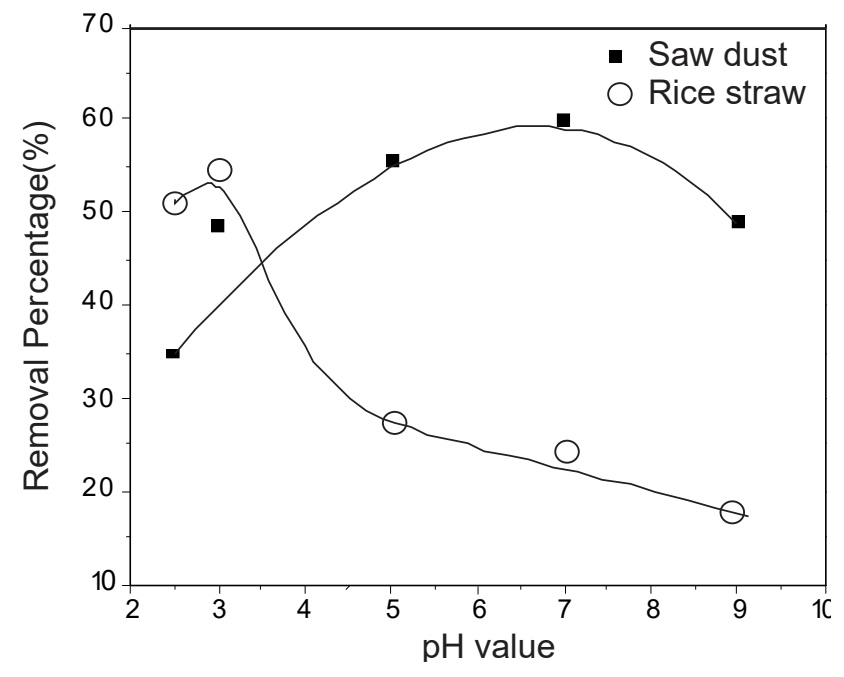

Figure 02: Variation of Removal Percentage(\%) of As(III) with $\mathrm{pH}$

For the As (III), the sorptions were 53\% and 59\% for biochars from rice straw and sawdust respectively. When $\mathrm{pH}$ close to 5, the binding sites of sawdust biochar became negatively charged due to presence of amino groups on the surface hence, the higher removal was recorded. Higher adsorption of As(III) ions onto rice straw biochar at lower $\mathrm{pH}$ may be due to attracting $\mathrm{AsO}_{3}{ }^{3-}$ ion onto higher positively charged metal binding sites.

\section{Influence of initial ion concentration on As (III) adsorption}

Removal percentages of arsenic ions onto saw dust and rice straw biochar were gradually increased with increased initial concentration of the metal solution (Figure 3). It was observed as a general trend that there is a decrease of the removal percentage with increase in initial concentration from $22 \mathrm{mg} / \mathrm{L}$. These results may be explained on the basis that the increase in the number of 
ions competing for the available binding sites and also because of the lack of active sites on the adsorbent at higher concentrations.

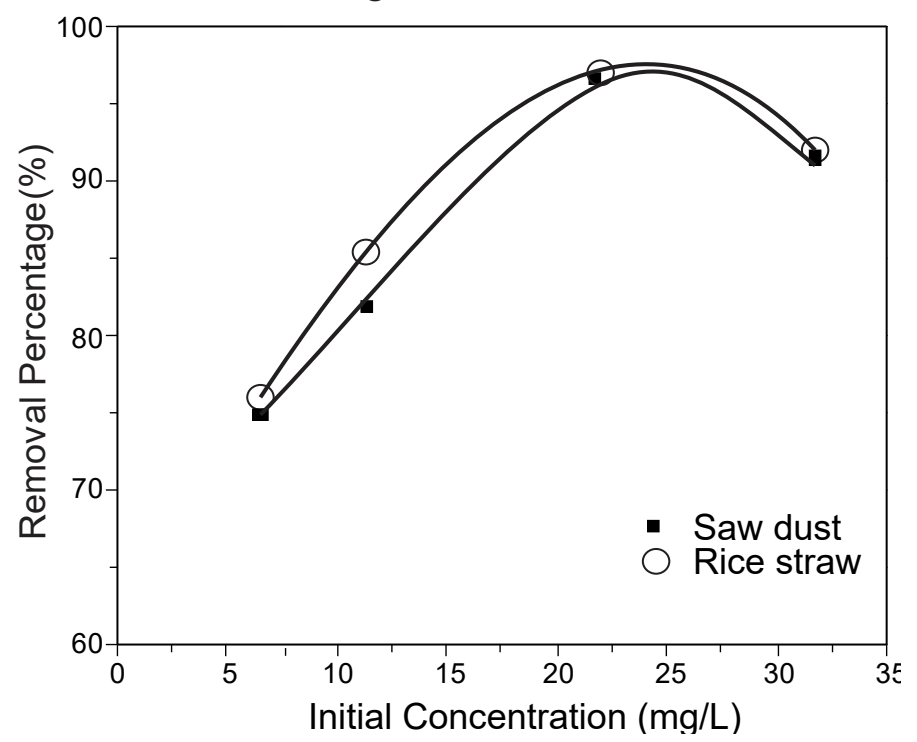

Figure 03: Variation of Removal Percentage( $\%$ ) of As(III) ions with Initial Ion Concentrations

\section{Sorption dynamics of As (III) ions}

Kinetics of adsorption is an important characteristic in defining the efficiency of adsorption. In order to explain the kinetics of biosorption pseudo second order kinetics model also was applied.

$$
\begin{aligned}
& \frac{d q_{\mathrm{t}}}{d t}=K_{2}\left(q_{e}-q_{\mathrm{t}}\right)^{2} \frac{d q_{\mathrm{t}}}{d t}=K_{2}\left(q_{e}-q_{\mathrm{t}}\right)^{2} \\
& \frac{\mathrm{t}}{q_{\mathrm{t}}}=\frac{1}{K_{2} q_{e}^{2}}+\frac{1}{q_{e}} t \frac{\mathrm{t}}{q_{\mathrm{t}}}=\frac{1}{K_{2} q_{e}^{2}}+\frac{1}{q_{e}} t
\end{aligned}
$$

Where, $K_{2}$ is the pseudo-second order rate constant. The slope and intercepts of the plot of $\mathrm{t} / \mathrm{q}_{\mathrm{t}} \mathrm{vs} \mathrm{t}$ (Figure 4 ) for adsorption of As (III) ions on saw dust and rice straw biochar were used to determine the value of $K_{2}$ and $q_{e}$ respectively. Values of correlation coefficient $\left(\mathrm{R}^{2}\right)$ and calculated values of $K_{2}$ and $q_{e}$ were (Table 01) indicated that pseudo-second order model is suitable to explain our experimental data. Values of $K_{2}$ for removal of As(III) ions for rice straw and saw dust biochar were 0.086 and 0.004 . 


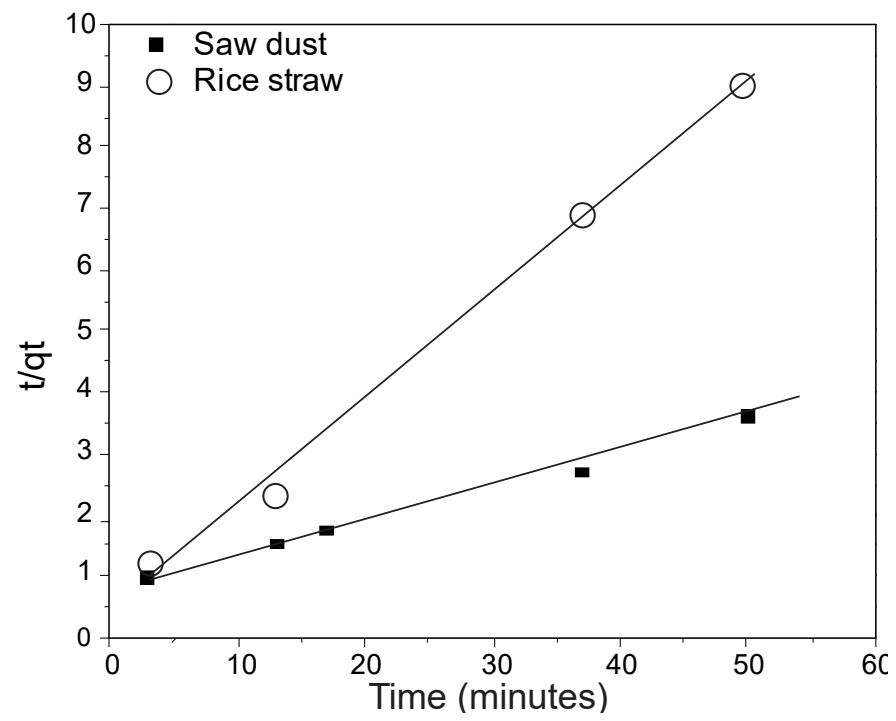

Figure 04: The graph of Time $t$ vs t/qt for As(III) ions

Table 01: Isotherm Parameters of different isotherms

\begin{tabular}{lccc}
\hline \multirow{2}{*}{ isotherm models } & \multirow{2}{*}{ Parameters } & \multicolumn{2}{c}{ Rice straw } \\
\cline { 3 - 4 } & & As (III) & As (III) \\
\hline Pseudo 2 $^{\text {nd }}$ & $\mathrm{K}_{2}$ & 0.004 & 0.086 \\
& $\mathrm{q}_{\mathrm{e}}$ & 1.38 & 5.78 \\
& $\mathrm{R}^{2}$ & 0.998 & 0.998 \\
Langmuir & $\mathrm{K}_{\mathrm{L}}$ & 2.19 & 12.07 \\
& $\mathrm{q}_{\max }$ & 8.89 & 9.09 \\
& $\mathrm{R}^{2}$ & 0.814 & 0.969 \\
Freundlich & $\mathrm{R}_{\mathrm{L}}$ & 0.995 & 0.999 \\
& $\mathrm{~K}_{\mathrm{F}}$ & 0.0018 & 0.0137 \\
& $\mathrm{~N}$ & 0.491 & 0.714 \\
& $\mathrm{R}^{2}$ & 0.987 & 0.990 \\
\hline
\end{tabular}

\section{Adsorption Mechanism}

Also the metal ions can be transported from aqueous phase to the solid phase by the intra-particle transport phenomenon. The intra-particle transport is supposed to be the rate controlling step. The rate of particle transport through this mechanism is slower than adsorption on the exterior surface site of the adsorbent. The amount of adsorbed species varies proportionately with a function of retention time. The equation can be expressed as .

$q_{e}=K_{d} t^{1 / 2}+C q_{e}=K_{d} t^{1 / 2}+C$ 
Where $\mathrm{K}_{\mathrm{d}}$ is the constant coefficient, the initial rate of intra-particular diffusion $\left(\mathrm{mg} / \mathrm{L} \cdot \min ^{1 / 2}\right)$. The transport of the adsorbents in aqueous solution through the biochar particle interface into the pores of the biochar particles, surface of the adsorbents, is responsible for adsorption.

Figure 5 illustrates the diffusion of As(III) ions within the saw dust and rice straw biomass as a function of time and shows that intra-particle diffusion occurred in adsorption process for saw dust and two stages for rice straw. The arsenic ions diffused quickly among the saw dust particles till the end. But it showed that the adsorption process at the beginning for movement of ions through rice straw particles and then intra-particle diffusion slowed till end. The slight deviation of these lines from origin indicates that As(III) removal controlled by both physical and chemical process.

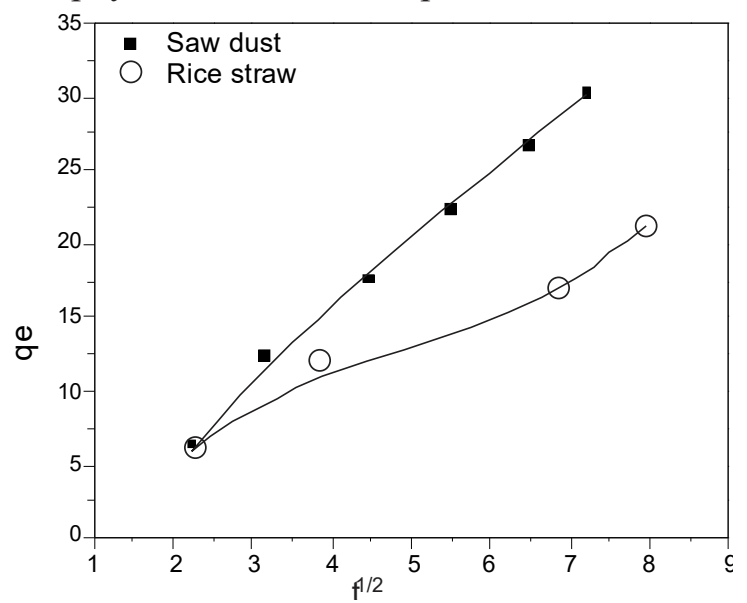

Figure 05: The graph of qe vs $\mathrm{t}^{1 / 2}$ for As(III) ions

\section{Conclusion}

The results of this study reveals that the percentage removal of As(III) ions were dependent on the $\mathrm{pH}$ of the solution and the initial metal concentration. The contact time necessary for maximum adsorption was ranged between 50 60 minutes for both materials. The optimum $\mathrm{pH}$ was 3 for recovery of As(III) ions. Kinetic studies yielded an optimum equilibrium time of 50 minutes with an adsorbent dose of $1 \mathrm{~g} / \mathrm{L}$ and initial concentration $\sim 20 \mathrm{mg} / \mathrm{L}$ for both ions. It can be concluded that metal ions in aqueous solution were transported to biochar surface through adsorption and intra-particle diffusion process. The sorption values indicated the affinity of the sorbent towards the uptake of As(III) ions and adsorptions of the metal ions were favorable.

\section{Acknowledgement}

This research was financially supported by the National Research Council in Sri Lanka (NRC) through a research grant (NRC 13-016). 


\section{References}

Aitio, A, and G Becking (2001), "Arsenic and Arsenic Compounds." World Health Organization Geneva 2001.

Badmus, MAO, TOK Audu, and BU Anyata (2007), "Removal of Lead Ion from Industrial Wastewaters by Activated Carbon Prepared from Periwinkle Shells (Typanotonus Fuscatus)." Turkish journal of engineering and environmental sciences 31, no. 4: 251-63. DOI: http:// dx.doi.org/10.1007/s11814-007-5049-5

Bailey, Susan E, Trudy J Olin, R Mark Bricka, and D Dean Adrian (1999), "A Review of Potentially Low-Cost Sorbents for Heavy Metals." Water research 33, no. 11: 2469-79. DOI: http://dx.doi.org/10.1016/s00431354(98)00475-8.

Bodek, I, W.J. Lyman, W.F. Reehl, and D.H. Rosenblatt (1988) Environmental Inorganic Chemistry. Properties, Processes and Estimations Methods. Pergamon Press: New York-Oxford. DOI: http://dx.doi.org/10.1002/ iroh.19900750509.

Bornemann, Ludger C, Rai S Kookana, and Gerhard Welp (2007), "Differential Sorption Behaviour of Aromatic Hydrocarbons on Charcoals Prepared at Different Temperatures from Grass and Wood." Chemosphere 67, no. 5: 1033-42. DOI: http://dx.doi.org/10.1016/j.chemosphere.2006.10.052

Bulut, Yasemin (2007), "Removal of Heavy Metals from Aqueous Solution by Sawdust Adsorption." Journal of Environmental Sciences 19, no. 2: 16066. DOI: http://dx.doi.org/10.1016/s1001-0742(07)60026-6

Chen, Baoliang, and Zaiming Chen (2009), "Sorption of Naphthalene and 1-Naphthol by Biochars of Orange Peels with Different Pyrolytic Temperatures." Chemosphere 76, no. 1: 127-33. DOI: http://dx.doi. org/10.1016/j.chemosphere.2009.02.004

Chen, Baoliang, Dandan Zhou, and Lizhong Zhu (2008), "Transitional Adsorption and Partition of Nonpolar and Polar Aromatic Contaminants by Biochars of Pine Needles with Different Pyrolytic Temperatures." Environmental science \& technology 42, no. 14: 5137-43. DOI: http:// dx.doi.org/10.1021/es8002684

Chen, Xincai, Guangcun Chen, Linggui Chen, Yingxu Chen, Johannes Lehmann, Murray B McBride, and Anthony G Hay (2011), "Adsorption of Copper and Zinc by Biochars Produced from Pyrolysis of Hardwood and Corn Straw in Aqueous Solution." Bioresource technology 102, no. 19: 8877-84. DOI: http://dx.doi.org/10.1016/j.biortech.2011.06.078 
Gao, Hui, Yunguo Liu, Guangming Zeng, Weihua Xu, Ting Li, and Wenbin Xia (2008), "Characterization of Cr (Vi) Removal from Aqueous Solutions by a Surplus Agricultural Waste-Rice Straw." Journal of Hazardous Materials 150, no. 2: 446-52. DOI: http://dx.doi.org/10.1016/j. jhazmat.2007.04.126

Garg, VK, Renuka Gupta, Rakesh Kumar, and RK Gupta (2004), “Adsorption of Chromium from Aqueous Solution on Treated Sawdust.” Bioresource technology 92, no. 1: 79-81. DOI: http://dx.doi.org/10.1016/j. biortech.2003.07.004

Klimmek, S, H-J Stan, A Wilke, G Bunke, and R Buchholz (2001), "Comparative Analysis of the Biosorption of Cadmium, Lead, Nickel, and Zinc by Algae." Environmental science \& technology 35, no. 21: 4283-88. DOI: http://dx.doi.org/10.1021/es010063x

Kołodyńska, D, R Wnętrzak, JJ Leahy, MHB Hayes, W Kwapiński, and Z Hubicki (2012), "Kinetic and Adsorptive Characterization of Biochar in Metal Ions Removal." Chemical Engineering Journal 197: 295-305. DOI: http://dx.doi.org/10.1016/j.cej.2012.05.025

Lee, CK, KS Low, and KL Kek (1995), "Removal of Chromium from Aqueous Solution." Bioresource technology 54, no. 2: 183-89. DOI: http://dx.doi. org/10.1016/0960-8524(95)00130-1

Lehmann, Johannes (2007), "Bio-Energy in the Black." Frontiers in Ecology and the Environment 5, no. 7: 381-87. DOI: http://dx.doi. org/10.1890/1540-9295(2007)5[381:bitb]2.0.co;2

Mohan, Dinesh, Charles U Pittman, Mark Bricka, Fran Smith, Ben Yancey, Javeed Mohammad, Philip H Steele, et al., (2007), "Sorption of Arsenic, Cadmium, and Lead by Chars Produced from Fast Pyrolysis of Wood and Bark During Bio-Oil Production." Journal of colloid and interface science 310, no. 1: 57-73. DOI: http://dx.doi.org/10.1016/j.jcis.2007.01.020

Oliveira, E.A., S.F. Montanher, A.D. Andrade, J.A. Nobrega, and M.C. Rollemberg (2005), "Equilibrium Studies for the Sorption of Chromium and Nickel from Aqueous Solutions Using Raw Rice Bran.” Process Biochemistry 40, no. 11: 3485-90. DOI: http://dx.doi.org/10.1016/j. procbio.2005.02.026

Rocha, Crystian Gonçalves, Dimas Augusto Morozin Zaia, Rení Ventura da Silva Alfaya, and Antonio Alberto da Silva Alfaya (2009), "Use of Rice Straw as Biosorbent for Removal of $\mathrm{Cu}$ (Ii), Zn (Ii), Cd (Ii) and $\mathrm{Hg}$ (Ii) Ions in Industrial Effluents." Journal of Hazardous Materials 166, no. 1: 383-88. DOI: http://dx.doi.org/10.1016/j.jhazmat.2008.11.074 
Šćiban, Marina, Bogdanka Radetić, Žarko Kevrešan, and Mile Klašnja (2007), "Adsorption of Heavy Metals from Electroplating Wastewater by Wood Sawdust." Bioresource Technology 98, no. 2: 402-09. DOI: http://dx.doi. org/10.1016/j.biortech.2005.12.014

Shukla, Alka, Yu-Hui Zhang, P Dubey, JL Margrave, and Shyam S Shukla (2002), "The Role of Sawdust in the Removal of Unwanted Materials from Water." Journal of Hazardous Materials 95, no. 1: 137-52. DOI: http://dx.doi.org/10.1016/s0304-3894(02)00089-4

Shukla, Shyam S, Li Jia Yu, Kenneth L Dorris, and Alka Shukla (2005), "Removal of Nickel from Aqueous Solutions by Sawdust." Journal of Hazardous Materials 121, no. 1: 243-46. DOI: http://dx.doi.org/10.1016/ s0304-3894(03)00008-6

Smedley, PL, and DG Kinniburgh (2002), "A Review of the Source, Behaviour and Distribution of Arsenic in Natural Waters." Applied geochemistry 17, no. 5: 517-68. DOI: http://dx.doi.org/10.1016/s0883-2927(02)00018-5

Smedley, PL, J Knudsen, and D Maiga (2007), "Arsenic in Groundwater from Mineralised Proterozoic Basement Rocks of Burkina Faso." Applied Geochemistry 22, no. 5: 1074-92. DOI: http://dx.doi.org/10.1016/j. apgeochem.2007.01.001

Smith, Allan H, Elena O Lingas, and Mahfuzar Rahman (2000), "Contamination of Drinking-Water by Arsenic in Bangladesh: A Public Health Emergency." Bulletin of the World Health Organization 78, no. 9: 1093-103.

Stollenwerk, Kenneth G (2003), "Geochemical Processes Controlling Transport of Arsenic in Groundwater: A Review of Adsorption." In Arsenic in Ground Water. 67-100: Springer. DOI: http://dx.doi. org/10.1007/0-306-47956-7_3

Sud, Dhiraj, Garima Mahajan, and M.P. Kaur (2008), “Agricultural Waste Material as Potential Adsorbent for Sequestering Heavy Metal Ions from Aqueous Solutions-a Review." Bioresource technology 99, no. 14: 601727.

WHO (1993), "Guidelines for Drinking Water Quality." 130. WHO Geneva.

Yadanaparthi, Sai Krishna Reddy, David Graybill, and Ray von Wandruszka (2009), "Adsorbents for the Removal of Arsenic, Cadmium, and Lead from Contaminated Waters." Journal of Hazardous Materials 171, no. 1: $1-15$.

Yu, Li Jia, Shyam S Shukla, Kenneth L Dorris, Alka Shukla, and JL Margrave (2003), "Adsorption of Chromium from Aqueous Solutions by Maple Sawdust." Journal of Hazardous Materials 100, no. 1: 53-63. 